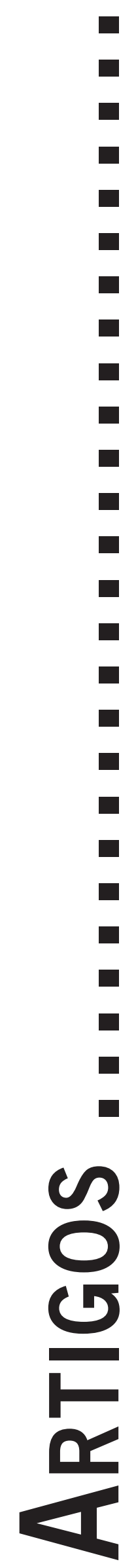




\title{
VIUVEZ E LUTO SOB A LUZ DA GESTALT-TERAPIA: EXPERIÊNCIAS DE PERDAS E GANHOS
}

\author{
Widowhood and Bereavement over Gestalt-Therapy Enlightening: Losses and Gaining Experiences
}

La Viudez y el Luto bajo la luz de la Terapia Gestalt: Experiencias de Pérdidas y Ganancias

LÍvia CARDOSO FERREIRA

Nara Cristina LeÃo

Celana Cardoso Andrade

\begin{abstract}
Resumo: O presente estudo é parte de uma pesquisa que abrangeu a dissolução do casal pela morte de um dos cônjuges e os benefícios atingidos com psicoterapia de abordagem gestáltica por pacientes enlutados. O objetivo deste artigo é abordar as experiências vividas pela pessoa que enfrenta o luto, especificamente pela morte do cônjuge. Além disso, intenciona-se investigar se a pessoa viúva pode obter benefícios com um acompanhamento psicoterapêutico na abordagem gestáltica. Seguese a metodologia qualitativa fenomenológica, de acordo com a proposta de Amedeo Giorgi (1985). Realizaram-se entrevistas, que foram gravadas, transcritas e analisadas, trecho a trecho, passando pelas quatro etapas propostas por Giorgi (1985). Os dados apresentados referem-se a experiência de uma das colaboradoras da pesquisa. Percebeu-se que a mesma obteve perdas e ganhos com a morte do marido e que a psicoterapia contribuiu para o enfrentamento e resolução do luto, sobretudo como um suporte ao viúvo(a), ao colaborar para que ele(a) ressignifique suas vivências, resgate o cuidado consigo mesmo e o interesse pela vida.
\end{abstract}

Palavras-chave: Luto; Viuvez; Método Fenomenológico; Gestalt-terapia; Psicoterapia.

Abstract: The present study it is part of a research that enclosed the dissolution of the couple for the death of one of the spouses, and the benefits reached with psychotherapy on Gestalt approach for bereaved patients. The objective of this article is to focus the experiences of a person dealing with mourning for the death of his/her spouse. Besides, it intends to investigate whether a widower may obtain benefits with psychotherapy on Gestalt approach. The phenomenological qualitative methodology is followed, in accordance with the proposal of Amedeo Giorgi (1985). There were made interviews, that had been recorded, transcribed and analyzed, in the four steps proposed by Giorgi (1985). The presented data refer to the experience of one of the collaborators of the research. She obtained losses and benefits with the death of the husband and the psychotherapy contributed for the confrontation and resolution of bereavement, above all as a support to the widower, by cooperating so that him/her would achieve experiences ressignification, and rescue the personal care, and interest in life.

Keywords: Bereavement; Widowhood; Phenomenological Method; Gestalt-therapy; Psychotherapy.

Resumen: El presente estudio fue parte de una pesquisa que abarcó la separación de la pareja por la muerte de uno de los cónyuges y los beneficios alcanzados con la psicoterapia gestalt de los pacientes enlutados. El objetivo de este artículo es abordar sobre las experiencias vividas por las personas que enfrentan el luto, específicamente por la muerte de un cónyuge. Además, se intencionó investigar si la persona viuda puede obtener beneficios con un acompañamiento psicoterapéutico desde el enfoque gestáltico. La metodología que se utilizó fue la cualitativa fenomenológica, de acuerdo con la propuesta de Amedeo Giorgi (1985). Se realizaron entrevistas, que fueron gravadas, transcriptas y analizadas, trecho por trecho, pasando por las cuatro etapas propuestas por Giorgi (1985). Los datos presentados se refieren a la experiencia de una de las colaboradoras de la pesquisa. Se percibió que la misma tuvo pérdidas e ganancias con la muerte del marido y que la psicoterapia contribuyó para el enfrentamiento y la resolución del luto, sobre todo, como un soporte a la viuda o al viudo, al colaborar para que él (ella) resignifique sus vivencias, rescate el cuidado consigo mismo (a) y el interés por la vida.

Palabras-clave: Luto; Viudez; Método Fenomenológico; Terapia gestalt; Psicoterapia.

O luto é uma resposta normal a um evento de vida inevitável - seu final - e se apresenta como uma reação à perda de uma pessoa amada (Parkes, 1998). Papalia e Olds (2000) explicam que a perda de uma pessoa significativa pode afetar praticamente todos os aspectos da vida do sobrevivente e definem luto como um processo de ajustamento.
Lira (2005) acredita que aquele que perde uma pessoa amada sofre uma experiência de luto diferente do paciente terminal - deve continuar existindo, e sua existência na ausência da pessoa perdida precisa ser readequada.

A questão central das reflexões deste estudo pode ser assim resumida: quando morre um dos membros do casal, o que acontece com aquele que fica? O objetivo deste 
artigo é abordar as experiências vividas pela pessoa que enfrenta o luto, especificamente pela morte do cônjuge. Além disso, intenciona-se investigar se a pessoa viúva pode obter benefícios com um acompanhamento psicoterapêutico na abordagem gestáltica.

É importante ressaltar que este artigo é parte de uma pesquisa que abrangeu a dissolução do casal pela morte de um dos cônjuges, e os benefícios atingidos com psicoterapia de abordagem gestáltica por pacientes enlutados. Os dados aqui apresentados referem-se a experiência de uma das colaboradoras da pesquisa.

Serão apresentadas algumas notas sobre o luto, com foco na viuvez, e sobre psicoterapia com enlutados na abordagem gestáltica. Os princípios da pesquisa qualitativa e do método fenomenológico serão abordados, seguidos pela apresentação da metodologia da pesquisa realizada. Os resultados e discussões levantados pelas pesquisadoras abrangem as experiências da colaboradora, ilustrada por trechos de sua fala, e os benefícios percebidos como resultantes do acompanhamento psicoterapêutico na abordagem gestáltica.

\section{Viuvez e Luto}

No casamento, um cônjuge conta com o outro como suporte afetivo e pessoal (Novo, 2003). De toda forma, é inevitável o momento em que esse sistema se desfaz, em decorrência do falecimento de um ou de ambos os cônjuges. A pessoa viúva fica sozinha, com a sensação de ser parte de uma unidade que já não existe mais concretamente (Lira, 2005).

O luto geralmente suscita reações de choque e incredulidade (incapacidade de acreditar na morte). Muitas pessoas experimentam um entorpecimento inicial, característico da dificuldade de aceitação da morte. A base do luto está na relutância em abrir mão de pessoas, planos, posses, expectativas e dos próprios papéis (Parkes, 1998).

Diante da perda de alguém à qual a pessoa se sente próxima, são suscitados sentimentos e manifestações corporais tais como dor, tristeza, choro fácil, respiração permeada por suspiros, apatia. Pessoas enlutadas ficam em estado de vigília elevado, experimentando inquietação, dificuldades de concentração, pavor e pânico (Eizirik, Michels \& Gazal, 1998; Lira, 2005; Parkes, 1998). É comum entre viúvas a perda de apetite e peso, dificuldades de sono, distúrbios digestivos, dores de cabeça, dores musculares, palpitações, sensação de ter um bolo no estômago, sensação de pressão na cabeça, irritação, ansiedade e tensão (Parkes, 1998).

A falta do cônjuge traz sensações subjetivas de insegurança, incapacidade e desproteção. Na ausência do outro, o cônjuge sobrevivente precisa lidar com a solidão, e a falta de alguém para compartilhar. A pessoa sente-se incapaz de realizar tarefas habituais, de enfrentar a vida. O pesar é tão forte por um tempo que se perde o contato com qualquer recurso de enfrentamento da situação, e tudo é vivido como dificuldade (Parkes, 1998).

A morte do marido pode representar a perda de um amor, de um confidente, de um bom amigo, do parceiro sexual, da fonte de renda, dependendo das expectativas e tarefas atribuídas ao cônjuge (Parkes, 1998). Há necessidade de aprender novos papéis, sem o apoio da pessoa com quem se costumava contar. Enfim, o luto é uma vivência de crise, e engloba alterações no nível de planos, hábitos, costumes, circunstâncias e comportamentos.

As sensações e experiências vivenciadas no luto permanecem com intensidade até que sejam encontradas fontes alternativas para a satisfação das necessidades pendentes (Parkes, 1998). Walsh (1995) declara que é necessário para o(a) viúvo(a) cumprir a tarefa de superação da tristeza pela perda, e reinvestir no funcionamento futuro, a fim de que caminhe no processo do luto para resolução. Lopata (1973, citado por Walsh, 1995) indica que é necessário desatar os laços com o marido e admitir que ele está morto, transformando lembranças em experiências compartilhadas.

Com o passar do tempo as demandas da realidade no funcionamento cotidiano e o manejo da estrutura doméstica se tornam foco. Por fim, novas atividades e interesses são bem recebidos pelo cônjuge sobrevivente, resultando um realinhamento no sistema familiar. A redescoberta de energia para investir mais intensamente nos papéis atuais ou em novos papéis é uma possibilidade que emerge com a resolução do luto (Parkes, 1998).

Outra tarefa para que a pessoa supere o luto é a expressão dos sentimentos provocados pela morte do cônjuge e esta idéia é sustentada por Parkes (1998); Cárdenas e Bravo (2005); Eizirik et al. (1998); e por Brown (1995). Esta é garantida por meio de uma rede de apoio familiar e/ou social que comporte o compartilhamento. A psicoterapia funciona nesse sentido, sendo que alguns autores alegam que o acompanhamento psicoterapêutico é de grande valia para enlutado (Brown, 1995; Cárdenas \& Bravo, 2005; Eizirik et al.).

\section{Psicoterapia com o Enlutado na Abordagem Gestáltica}

Grande parte das abordagens psicoterapêuticas abrange um diálogo com as experiências pessoais na busca de resolução dos conflitos e pode atingir sucesso no trabalho com enlutados (Brown, 1995; Eizirik et al., 1998; Zinker, 2001). Neste artigo, será focada a abordagem gestáltica, sem o interesse de compará-la com outras orientações teórico-filosóficas, uma vez que esse não é o objetivo deste estudo. Assim, faz-se importante a contextualização de alguns pressupostos que norteiam o trabalho da Gestalt-terapia.

A forma gestáltica de trabalhar fundamenta-se na crença de que o homem é um ser em relação, presente no 
mundo, repleto de possibilidades e apto a conhecer-se, a realizar suas escolhas e a dirigir sua vida. Para a Gestaltterapia, o cliente deve descobrir o sentido de sua vida (sentimentos, pensamentos e ações) no contexto atual, e ampliar sua consciência acerca de si mesmo, de sua forma de existir, e de suas relações (Yontef, 1998).

Junto a um gestalt-terapeuta, a pessoa viúva compartilha, discute, revê e busca maior clareza dos significados de cada experiência vivenciada em torno da morte do cônjuge. Os esforços são voltados à compreensão da experiência atual e dos impactos da morte sobre o cônjuge sobrevivente. O objetivo é rever, da melhor forma possível, as questões concretas de seu cotidiano (sua dor, seu desespero, sua angústia, sua necessidade de escolher, de superar seus limites etc.), mediante uma metodologia clínica investigativa e esclarecedora da experiência (Perls, Herffeline \& Goodman, 1997).

A Gestalt-terapia é um modelo pautado pela filosofia fenomenológico-existencial. Clientes e terapeutas estão, necessariamente, em diálogo, isto é, comunicam suas perspectivas um ao outro, com o propósito de mostraremse o mais verdadeiramente possível. Tal relação é pautada no respeito pela experiência do outro, na comunicação direta e genuína, no suporte para que o cônjuge sobrevivente possa falar e contatar suas vivências. A atitude do terapeuta é de escuta respeitosa e não judicativa, acolhendo e investigando a experiência do outro e permitindo a expressão livre de sentimentos, idéias, vontades, entre outros (Hycner, 1995; Yontef, 1998). Uma visão real da pessoa que morreu e também do contexto atual de vida, bem como a possibilidade de expressar-se e ser ouvido sem ser julgado, facilita a resolução do luto e a adaptação à perda (Brown, 1995; Eizirik et al., 1998; Parkes, 1998; Cárdenas \& Bravo, 2005; Zinker, 2001).

\section{Pesquisa Qualitativa}

Para a realização deste estudo, foi escolhida a pesquisa qualitativa como forma de investigar a experiência da colaboradora e atingir os objetivos dessa investigação com sujeito humano. $\mathrm{O}$ método de pesquisa utilizado será o fenomenológico, seguindo o modelo de Giorgi (1985).

A pesquisa qualitativa fenomenológica busca a compreensão da experiência do sujeito a partir da essência do fenômeno, que é trazida pelo próprio colaborador. A proposta do método de pesquisa fenomenológica de Amedeo Giorgi (1985) fornece uma maneira de se concretizar a investigação, seguindo-se a concreta descrição da experiência de forma cuidadosa.

O método de Giorgi (1985) contém quatro passos. No primeiro, faz-se uma leitura da descrição completa da experiência para se obter o senso geral da fala. Tendo compreendido o senso do todo, o pesquisador relê o texto com o objetivo específico de discriminar "unidades de sentido" a partir de uma perspectiva psicológica e com foco no fenômeno que está sendo pesquisado. As unidades significativas emergem sempre que se percebe uma mudança psicologicamente sensível de significado da situação para o sujeito. Holanda (2002) postula que as unidades de significado não existem soltas, mas em relação à perspectiva adotada pelo pesquisador. Essas unidades são constitutivas do texto e não apenas elementos isolados. Nesse segundo passo, a linguagem do sujeito quase não é mudada, e as discriminações são feitas espontaneamente. As falas são sumarizadas, respeitando as expressões da colaboradora.

No terceiro, volta-se a todas as unidades de sentido e expressa-se uma percepção psicológica a seu respeito. Nesse momento, a linguagem do dia-a-dia é transformada em linguagem psicológica. Segundo Giorgi (1985), esse é o momento mais revelador do fenômeno estudado, já que nele faz-se uma leitura deste. No quarto e último passo, o pesquisador sintetiza todas as unidades de sentido, transformando-as em categorias, que correspondem ao agrupamento de unidades de significado, na busca de traduzir, de uma maneira mais ampla, o que aqueles pareciam transmitir.

Contextualizando esta pesquisa em particular, serão apontadas em seguida algumas questões da metodologia.

\section{Metodologia}

O primeiro pré-requisito estabelecido na escolha da colaboradora era que fosse uma mulher viúva e que fizesse psicoterapia na abordagem gestáltica. Foi realizada uma entrevista, em consultório psicológico, por esse ser um ambiente que proporciona privacidade. No primeiro momento da entrevista, foi apresentada à colaboradora a proposta de pesquisa e obtido o consentimento para participação e divulgação dos dados, mediante a assinatura do termo de consentimento da participação da pessoa como sujeito.

A coleta de dados foi feita por meio de entrevista semiaberta, com as seguintes questões norteadoras: 1) Como foi a vivência do seu casamento? 2) Quais as experiências vividas com a viuvez? (positivas e negativas) 3) Em que momento buscou a psicoterapia? 4) Como a psicoterapia auxiliou nas experiências advindas da morte do cônjuge? A escolha de tal instrumento se deu em função da possibilidade de expressão por meio de um diálogo aberto, livre de focos rígidos, respeitando os princípios da pesquisa qualitativa fenomenológica.

Para maior fidedignidade na obtenção e apresentação dos dados, fez-se a gravação da entrevista, com a permissão da colaboradora, e sua transcrição na íntegra. Os dados foram analisados segundo a metodologia de Giorgi, e chegou-se a algumas categorias de acordo com o objetivo do trabalho. Para melhor compreensão do estudo, foi feito um breve histórico, com informações 
que contextualizam a situação da colaboradora. O nome citado é fictício, no sentido de resguardar a identidade da participante.

\section{Tereza}

Tereza é uma mulher de 54 anos. Foi casada por trinta e três anos e teve cinco filhas. Descreve seu casamento como "um tempo muito bom" - eram raras as situações de conflito e a compreensão era muito presente na relação do casal. Tereza acrescenta que vivia uma relação de intensa dependência do marido, sempre precisando da palavra dele para saber como agir.

O cônjuge tinha problema cardíaco, ficou em tratamento por mais ou menos dezoito anos e faleceu há pouco mais de quatro anos. Sofreu mais de um Acidente Vascular Cerebral (AVC), o que o deixou muito debilitado e dependente dos cuidados de Tereza. Ela sofreu muito devido ao adoecimento e contínua piora no quadro do marido, e se manteve muito perto dele enquanto estava doente, permanecendo presente até a sua morte. Demonstra ter tido grande preocupação e cuidado com o mesmo.

Após o falecimento de seu marido, ela ficou muito debilitada, emocional e fisicamente. Demonstrou dificuldade de aceitar a situação, perda da vontade de se alimentar, alterações do sono, apatia, falta de ânimo e alegria, bem como sintomas psicossomáticos, a saber, dores pelo corpo, fraqueza muscular e eventuais quedas.

Tanto no período da doença, quanto depois da morte de seu marido, Tereza se esforçou para esconder seus sentimentos. Quando cuidava do esposo, não chorava perto dele para que ele não percebesse seu sofrimento. Após sua morte, evitava chorar na frente de outras pessoas, principalmente das filhas, para que ninguém percebesse sua dor. Ela tinha a fantasia de que se as filhas a vissem chorando, sofreriam ainda mais.

A psicoterapia foi buscada alguns meses após a morte de seu marido, quando, enfim, ela não conseguiu conter seus sentimentos e os expressou. Suas irmãs, vendo sua dor, sugeriram que ela buscasse acompanhamento psicológico, ao que ela atendeu. Tereza está em processo psicoterapêutico na abordagem gestáltica há quase três anos. No início do processo, apresentava constantemente sintomas depressivos desencadeados pela viuvez. Atualmente, percebe-se ainda, em alguns momentos, enfraquecida triste, abatida e com vontade de morrer. Porém, com a ajuda da terapia, tem resgatado em si a vontade de viver e o interesse pela vida.

A seguir são apresentados os resultados relevantes ao objetivo. Há palavras e expressões em negrito, as quais são as categorias resultantes da narrativa da colaboradora. As categorias, advindas das unidades de sentido, são os nomes dados aos temas experienciais da entrevistada, que são encontrados na última etapa da investigação pelo método de Amedeo Giorgi (1985). As categorias são apresentadas em subtítulos para melhor visualização e são exemplificadas com as falas da viúva colaboradora, que aparecerão entre "aspas" ou destacadas. Algumas discussões são incitadas pelas pesquisadoras, em vista das teorias acessadas.

\section{Resultados e Discussão}

\section{A Vivência do Casamento}

A experiência da colaboradora no casamento mostrou-se bastante positiva. Ao descrever seu relacionamento conjugal, Tereza fala de um vínculo de proximidade, compartilhamento, apoio, cuidado mútuo, preocupação e dependência com seu esposo:

Tinha, às vezes, alguma discussão, mas era coisa, assim, rara. Não era muito. Ele mesmo era uma pessoa muito compreensiva comigo. A gente sempre sabia entender um ao outro. (...) Pra mim isso foi assim... um tempo muito bom.

(...)

(...) ele ia fazer muita falta pra mim. De ser aquela pessoa amiga, companheira que eu tinha. (...) Que mesmo que ele tava doente, deitado numa cama, mas geralmente eu ia aonde ele tava e pedia orientação pra ele (...). Às vezes, eu teria que fazer uma coisa, e não tinha certeza se ia estar certo do jeito que eu estava imaginando, e quando ele estava, eu conversava com ele: - "Você acha que isso está certo assim, ou não? O que você acha que eu devo fazer?"

\section{A Morte do Cônjuge}

Com a perda do parceiro, o cônjuge sobrevivente inicia o processo de luto. Parkes (1998) define luto como a resposta a um evento natural da vida - a morte de uma outra pessoa. Tereza não aceitava a morte do marido vivia um conflito entre a idéia de que era a vontade de Deus e a sua vontade de que ele ficasse curado. Apesar de perceber que ele iria morrer, tinha muita dificuldade em aceitar isso.

Para Carr et al. (2000), a forma como a pessoa ajusta-se psicologicamente a essa etapa é influenciada pela qualidade da relação conjugal. Tereza e o marido possuíam um vínculo construtivo - narra experiências de amabilidade e dependência instrumental no casamento, demonstra uma ligação forte com o marido falecido e traz muitos detalhes da convivência. Percebe-se, na entrevista de Tereza, que ela apresentou dificuldade para ajustar-se à perda do marido. Ela conta que se perguntava: - "como eu ia conseguir sobreviver sem ele."

Tereza demonstra pesar e sintomas depressivos relacionados ao falecimento do marido - perda de alegria, vontade e entusiasmo; perda da vontade de fazer algo por si própria, como ir a passeios, preferindo ficar sozinha. Alguns trechos ilustram: 
Até hoje ainda tem momento que eu sinto. Eu chego a não sentir mais vontade de viver, eu perdi a vontade de viver, nada, parece que mais nada teria sentido eu aqui, sabe? (...)

Eu não sou mais aquela pessoa alegre que eu era.(...) Eu perdi o entusiasmo de muitas coisas que às vezes eu gostaria de fazer, hoje não... Hoje parece que tudo é mais difícil pra mim, até o passeio se torna difícil ir. Perdi o interesse de várias coisas. Por mais que eu estivesse num ambiente que todo mundo está feliz, está sorrindo, eu estou, às vezes junto com aquelas pessoas, mas dentro de mim não existe essa alegria.

Um outro dado observado na entrevista é relativo às alterações na saúde do cônjuge sobrevivente. Holmes e Masuda (1973, citado por Brown, 1995) são autores que descreveram alta correlação entre eventos no ciclo de vida familiar e alterações na saúde do indivíduo. Com Tereza fica nítido: - "Quantas madrugadas eu levantava no meu quarto, chorava, chorava. O sono desaparecia, não tinha sono pra dormir. Às vezes quando eu conseguia dormir um pouco, o dia tava quase amanhecendo, aí eu conseguia dormir um pouco."

Quando questionada a respeito de sua saúde, Tereza responde: - "Muito abalada! Até hoje eu não sinto ainda que eu vivo o que eu vivia antes. Qualquer emoção que eu tiver, eu endureço, uma coisa, assim, de cair." Quando Tereza se emociona, seu corpo manifesta sintomas psicossomáticos: enrijecimento, dor, tensão, paralisia, enfraquecimento, seguidos de quedas recorrentes: "uma hora parece que eu estava suportando melhor, outra hora chegava aquele momento assim, que estava beirando o caixão dele [velório], e de repente, eu estava caída no chão."

Tereza tem aprendido a lidar com a realidade de ser uma mulher viúva, a qual considera difícil. Seu marido costumava dar-lhe orientações sobre como ela deveria agir. Após sua morte, perdeu esse apoio, sentiu-se sem suporte e ficou com a fantasia de que não conseguiria resolver algumas questões sem ele, sentindo-se incapaz de lidar com as demandas familiares e de cuidado com a casa. A necessidade de assumir novos papéis e responsabilidades adicionais - que antes eram do marido, e/ou eram divididas - são mudanças significativas (Carr et al., 2000), e tomaram grande espaço na vida de Tereza.

Ser uma mulher viúva não é fácil, que se torna aquelas responsabilidades que era entre eu e ele, ficou pra mim. Tem momento que às vezes eu sei como ir conduzindo. Em outros momentos que parece que eu num vou dar conta, sabe? (...) Às vezes eu fico indecisa, o que é que eu tenho que fazer, o que vai dar certo.

É comum a correlação das experiências atuais com a morte do cônjuge: - "Tudo eu sinto que foi causado pela falta dele". - "Porque tinha uns dia que eu ficava pensando assim, mas o que é que eu estou fazendo aqui com tanta tristeza, tanta dor que eu sinto. Eu sei que tudo isso é causado pela morte dele".
Atualmente, seus sintomas e sentimentos negativos ainda estão presentes, porém em menor intensidade. Mesmo com todo o sofrimento referente à perda do marido, Tereza obteve alguns ganhos pessoais. Papalia e Olds (2000) explicam que a viuvez proporciona experiências de desenvolvimento, como a confiança em sua própria capacidade de resolver as questões do dia-a-dia. Tereza descreve sua experiência - "Naquela época eu acho que eu era muito (...) dependente da vida dele, (...) da palavra dele, em como eu ia agir. Agora, que eu não tenho ele mais, que eu estou sozinha, em vários aspectos, eu tenho que tomar atitude".

\section{Resolução}

Ao vivenciar seu processo de luto, a pessoa viúva passa por diversos sentimentos. Aos poucos, ela começa a aceitar a realidade da morte, o que abre espaço para o resgate do interesse pelas atividades do dia-a-dia. Papalia e Olds (2000) denominam esse momento como resolução de questões psicológicas relacionadas à perda. Parkes (1998) acrescenta que, com a resolução, a pessoa é capaz de conquistar um crescimento significativo, como um ser autônomo, e enfim assumir uma nova identidade.

Dessa forma, mesmo que ainda sinta falta de seu cônjuge, o viúvo consegue seguir com sua vida e tornar-se socialmente mais ativo. Ocorre a retomada de interesses antigos e a descoberta de novos. Tereza percebe em si essa questão: - "Então voltou esse interesse pela vida". $\mathrm{Na}$ resolução, as lembranças de seu parceiro despertam uma tristeza misturada a afeição, e não mais dor aguda, como antes, o que possibilita ao viúvo a retomada da vida com maior ânimo.

Para chegar ao ponto da resolução, é importante que a pessoa viúva conte com uma rede de apoio. Parkes (1998) considera o apoio social e o isolamento fatores determinantes na vivência do luto, ressaltando a rede de apoio como facilitadora do processo. Essa rede é formada por familiares, vizinhos, amigos, dentre outros. $\mathrm{O}$ apoio das pessoas traz uma sensação de segurança para o viúvo, pois este percebe que não está sozinho nesse momento tão difícil.

\section{Processo Psicoterapêutico}

Tereza procurou a psicoterapia incentivada pela rede de apoio familiar, o que confirma a importância da rede para a pessoa viúva. Ela conta como aconteceu:

(...) uma das minhas irmã disse: - 'Olha, um dia eu fui na cabeleireira, e ela falou pra mim que lá na P. S. tem psicólogo que pode ajudar as pessoa que tão precisando, no seu caso, tem quem pode te ajudar (...). Aí quando foi na segunda-feira uma sobrinha minha ligou. 
A colaboradora demonstrou em sua entrevista ter uma experiência positiva do processo psicoterapêutico. No seu depoimento, fica explícito seu engajamento na psicoterapia, o que facilita o processo de resolução do luto.

A colaboradora fala sobre sua vivência da psicoterapia:- "Olha, tem sido maravilhoso! Tem certos dias que eu fico assim pensando, se eu não tivesse essa ajuda, como eu poderia está... Às vezes eu nem estava sobrevivendo mais. (...) Tá funcionando maravilhoso".

Tereza buscou a psicoterapia com uma demanda diretamente relacionada à viúvez - com a morte do marido, perdeu o sentido da vida. A colaboradora relatou que no início do processo psicoterapêutico, manifestava sintomas depressivos e muito sofrimento - "No começo da terapia, sentia uma vontade imensa de morrer, que não tinha sentido eu ficar aqui, que o C. tinha morrido, que..., por quê eu fiquei aqui?"

Tereza está em psicoterapia há três anos, e sua narrativa evidencia a existência de um bom vínculo terapêutico - "A doutora, tem sido sempre uma mão amiga (...) A doutora tem sido um anjo na minha vida, sabe? Em muitas coisas assim, ensina eu até a viver. (...) Eu sempre falo, agradeço muito a Deus".

A partir da entrevista de Tereza, percebe-se a vivência da relação dialógica na psicoterapia. Nesse tipo de relação, há respeito pela singularidade do outro. Hycner (1995) considera o desejo e a capacidade de estabelecer relacionamentos significativos como o ponto central da existência humana. Ele acrescenta que a vivência de tais relacionamentos é por si só curadora.

Brown (1995) ressalta a comunicação franca e direta por parte do psicoterapeuta, com evitação de eufemismos e termos indiretos, como fundamental ao processo psicoterapêutico com pessoas enlutadas. Ele defende que esse tipo de comunicação serve de modelo para a viúva e sua família. Zinker (2001) prioriza a presença do psicoterapeuta como testemunha que ouve respeitosamente, acompanha o processo do cliente, sem pressionar uma finalização precoce do luto. O psicoterapeuta torna-se, então, um suporte para que o cônjuge sobrevivente possa falar e contatar cada aspecto vivenciado.

De acordo com Brown (1995), um aspecto que merece investigação, são as relações com a pessoa que morreu, já que é comum que o morto seja idealizado ou denegrido. Dessa forma, o psicoterapeuta pode auxiliar o indivíduo a resgatar uma visão equilibrada da pessoa que morreu e também uma clareza acerca dos eventos em torno da morte (Eizirik et al., 1998).

\section{Benefícios Obtidos com a Psicoterapia}

A compreensão que a pessoa viúva vivencia no processo psicoterapêutico possibilita a ressignificação de suas experiências. Segundo Bandler e Grinder (1986), ressignificação é a modificação da forma que a pessoa percebe os acontecimentos, resultando em alteração do significado. Em decorrência da mudança do significado, comportamentos e respostas da pessoa se modificam.

Amorim (2004) afirma que a ressignificação traz liberdade à pessoa, de modo que ela passa a viver de maneira mais saudável, relacionando-se melhor com o mundo. Durante o processo psicoterapêutico com pessoas viúvas, suas histórias são intensamente revisitadas, dessa vez na companhia de um psicoterapeuta. À medida que a pessoa reconstrói sua história, o psicoterapeuta torna-se um parceiro de vida muito especial, testemunha de sua existência (Juliano, 1999; Zinker, 2001).

A partir da ressignificação de suas vivências, o cônjuge sobrevivente desperta a capacidade de conduzir a si mesmo, aprendendo a identificar suas necessidades e a buscar possíveis soluções (Juliano, 1999). Duas falas de Tereza ilustram: - "Se é pra fazer alguma coisa, eu tenho que ver se eu vou dar conta de fazer e eu tenho que agir nisso. (...) Aí, eu sinto que ele faz muita falta. Mas a gente arranjou um outro jeito de conseguir fazer." Percebe-se em sua vivência experiências de superação, relacionadas tanto a resolução de problemas cotidianos, quanto aos sentimentos evocados pela perda. Atualmente, Tereza apresenta uma maior força para enfrentar as dificuldades.

Entende-se que a colaboradora experimentou, por meio da experiência da psicoterapia, um resgate significativo da vontade de viver e do interesse pela vida. Isso fica claro na fala de Tereza, no momento em que esta faz uma comparação de como se sentia antes de iniciar o processo psicoterapêutico, e como se sente agora:

Depois da terapia, voltou essa vontade de viver. Tem momentos que às vezes eu fraquejo, eu me sinto muito triste, às vezes, volta o pensamento, mas no começo, eu pensava direto: - "Eu não queria estar viva, eu queria morrer". Hoje não, isso é uma coisa que eu sinto nascer, com a ajuda da terapia. (...) Voltou esse interesse pela vida.

Sintomas depressivos eram uma constante na vida de Tereza. Eventualmente, ainda sente-se deprimida, no entanto, relata que em função da psicoterapia tem experimentado grandes melhoras.

\section{Considerações Finais}

Percebe-se que o luto pela morte de um dos cônjuges é um processo doloroso. Exige uma reconfiguração da identidade do cônjuge sobrevivente, que deixa de ser esposo(a) e passa a ser viúvo(a). Muitas mudanças acontecem na vida desse indivíduo que precisa elaborar uma perda, não só de seu marido/mulher, mas de sua configuração de vida, além de responder às novas tarefas impostas com a viuvez.

Em meio a ganhos e perdas, o cônjuge sobrevivente tem vários tipos de experiência e vivencia diversos sentimentos. A experiência de Tereza revela sofrimento, dor, 
dificuldades de aceitação, alterações de saúde e de sua total situação e rotina de vida. Experimenta a viuvez com um senso de perda muito forte.

Contudo, há também aspectos positivos em meio a esse processo. Tereza se percebe capaz de resolver algumas coisas e sente-se feliz com isso. Ganhou autonomia com a situação da viuvez, tomando atitudes, muitas vezes de forma independente, sempre que é necessário. Foi possível perceber uma reconfiguração do campo familiar - Tereza e suas filhas atualmente trocam experiências, compartilham dificuldades e tornaram-se cúmplices na vida em comum.

Diante do objetivo deste artigo - abordar as experiências vividas pela pessoa que enfrenta o luto especificamente pela morte do cônjuge, entende-se que no processo de viuvez, podem haver, além da dor causada pelo luto, conquistas, que relacionadas a questões de autonomia, crescimento, independência e formação de novos papéis.

A elaboração de novos vínculos ou mesmo o fortalecimento de relações antigas também é de grande relevância, visto que, para elaborar o luto, o cônjuge sobrevivente necessita de uma rede de apoio. $\mathrm{O}$ processo psicoterapêutico de base gestáltica funciona como um suporte ao viúvo(a), que colabora para que ele(a) possa ressignificar suas vivências e resgatar o cuidado consigo mesmo(a), e o interesse na vida. Tereza tem percebido melhoras em sua saúde e as atribui à ajuda de pessoas de sua convivência e de profissionais da área de saúde, como sua psicoterapeuta.

No tocante a abordagem psicoterapêutica, considerase que a Gestalt-terapia é indicada para o tratamento de pessoas enlutadas. Em especial, pelo caráter dialógico, que pressupõe um tipo de relação que presume uma atitude acolhedora, de escuta respeitosa e não judicativa, descritas por Hycner (1995); Jacobs (1997) e Yontef (1998) e favorece a expressão livre de sentimentos, idéias e vontades, que é considerada crucial na elaboração do luto (Parkes, 1998; Cárdenas \& Bravo, 2005).

Tereza refere-se ao processo psicoterapêutico como uma experiência positiva. Questiona-se como estaria sua vida se não contasse com essa ajuda. Ao chegar ao consultório sente-se ajudada, apoiada, fortalecida e mais animada. É notório que a ajuda que ela diz ter encontrado no relacionamento com sua psicoterapeuta foi determinante no resgate em si da vontade de viver e do interesse pela vida.

Em suma, é possível perceber que a pessoa viúva pode obter benefícios com um acompanhamento psicoterapêutico na abordagem gestáltica. Verificou-se que a psicoterapia serve como um grande auxílio para a pessoa viúva no processo de resolução do luto. Acontecem ressignificações que abrem espaço para o surgimento de novas possibilidades.

As pesquisadoras consideram que foi imprescindível seguir criteriosamente cada etapa da metodologia postulada por Giorgi (1985), pois esta proporcionou maior clareza e compreensão sobre os temas acessados. A busca da experiência da pessoa - a exploração daquilo que é vivido, da maneira como se desvela, sem a imposição de preconcepções e julgamentos - garantiu a riqueza dos dados coletados e apurados.

\section{Referências Bibliográficas}

Amorim, T. C. G. W. (2004). A terapia familiar focal: pais/filhos e irmãos. Revista do X Encontro Goiano da Abordagem Gestáltica, 10, 99-104.

Bandler, R. \& Grinder, J. (1986). Resignificando - programação neurolinguística e a transformação do significado. São Paulo: Summus.

Brown, F. H. (1995). O impacto da morte e da doença grave sobre o ciclo de vida familiar. Em B. Carter \& M. McGoldrick (Orgs.). As mudanças no ciclo de vida familiar: uma estrutura para a terapia familiar ( $2^{\mathrm{a}}$ ed., pp. 393-412). Porto Alegre: Artes Médicas.

Cárdenas, C. P. \& Bravo, P. L. (2005). Aspectos de interés para la vida de las personas viudas. Revista Cubana de Medicina General Integral. [online]. 21 (3-4). Disponível em http://scielo.sld.cu/scielo.php?script $=$ sci_arttext\&pid $=$ S0864212520 05000300006\&lng $=$ es\&nrm $=$ iso\&tlng $=$ es .

Carr, D., House, J. S., Kessler, R. C., Nesse, R. M., Sonnega, J. \& Wortman, C. (2000). Marital Quality and Psychological Adjustment to Widowhood Among Older Adults: A Longitudinal Analysis. Journal of Gerontology: social sciences. 55B (4), 197-207. Disponível em: http://psychsoc.gerontologyjournals.org/cgi/content/full/55/4/S197.

Eizirik, C. L., Michels, A. M., \& Gazal, C. H. (1998). Psicoterapia do luto normal e patológico. Em A. V. Cordioli (Org.). Psicoterapias: abordagens atuais. (2 ${ }^{\mathrm{a}}$ ed.). Porto Alegre: Artes Médicas.

Giorgi (1985). Sketch of a psychological phenomenological method. Em A. Giorgi (Org.). Phenomenology and psychological research (pp. 8-22). Pittsburg: Duquesne University Press.

Holanda, A. (2002). O resgate da Fenomenologia de Husserl e a pesquisa em Psicologia. Tese de Doutorado em Psicologia. Pontifícia Universidade Católica de Campinas (PUCCampinas), Campinas.

Hycner, R. (1995). De pessoa a pessoa: psicoterapia dialógica. São Paulo: Summus.

Juliano, J. C. (1999). A arte de restaurar histórias. São Paulo: Summus.

Jacobs, L. (1997). O diálogo na teoria e na Gestalt-terapia. Em R. Hycner \& L. Jacobs, Relação e cura em Gestalt-terapia (pp. 67-94). São Paulo: Summus.

Lira, M. G. (2005). El apego. Ars medica: Revistia de estúdios médicos humanísticos. 11(11), 107-117. Disponível em: http://escuela.med.puc.cl/publ/ArsMedica/ArsMedica11/ Ars06. html. 
Novo, (2003). Para além da eudaimonia - o bem estar psicológico em mulheres na idade adulta avançada. Coimbra: Fundação Calouste Gulbenkian.

Papalia, D. E. \& Olds, S. W. (2000). Desenvolvimento humano. Porto Alegre: Artes Médicas Sul.

Parkes, C. M. (1998). Luto: estudos sobre a perda na vida adulta. São Paulo: Summus.

Perls, F., Hefferline, R. \& Goodman, P. (1997). Gestalt-terapia. São Paulo: Summus.

Walsh, F. (1995). A família no estágio tardio de vida. Em B. Carter \& M. McGoldrick (Orgs.). As mudanças no ciclo de vida familiar: uma estrutura para a terapia familiar $\left(2^{\mathrm{a}} \mathrm{ed}\right.$., pp. 269-284). Porto Alegre: Artes Médicas.

Yontef, G. M. (1998). Processo, diálogo, awareness. São Paulo: Summus.

Zinker, J. C. (2001). A busca da elegância em psicoterapia: uma abordagem gestáltica com casais, famílias e sistemas íntimos. São Paulo: Summus.

Lívia Cardoso Ferreira - Psicóloga, graduada pela Universidade Católica de Goiás, especialista em Gestalt-terapia e em Psicoterapia de Criança, Casal e Família pelo Instituto de Treinamento e Pesquisa em Gestaltterapia de Goiânia (ITGT/UCG).

E-mail: licarfer2@yahoo.com.br

Nara Cristina Leão - Psicóloga, graduada pela Universidade Católica de Goiás, especialista em Gestalt-terapia e em Psicoterapia de Criança, Casal e Família pelo Instituto de Treinamento e Pesquisa em Gestaltterapia de Goiânia (ITGT/UCG).

E-mail: leaonara@yahoo.com.br

Celana Cardoso Andrade - Psicóloga, especialista em Psicologia Clínica, Gestalt-terapeuta, formada pelo Instituto de Treinamento e Pesquisa em Gestalt-terapia de Goiânia (ITGT). Professora do Curso de Especialização do ITGT. Organizadora dos Encontros Goianos da Abordagem Gestáltica. Mestre em Psicologia Clínica pela Universidade Católica de Goiás (UCG). Psicoterapeuta na Alter - Consultórios de Psicologia.

E-mail: celana@terra.com.br

Recebido em 09.09.08

Primeira Decisão Editorial em 28.02.09

Aceito em 12.04.09 